\title{
Study on the Significance of Network Literature in the Development of Chinese Contemporary Literature
}

\author{
Jun $\mathrm{TaO}^{1, \mathrm{a}}$ \\ ${ }^{1}$ Nanchang Institute of Science and Technology, Nanchang, Jiangxi, 330108 \\ a email
}

Keywords: Network Literature, Chinese Contemporary Literature, Development Meaning

\begin{abstract}
With the continuous development of the current Internet technology and popularization of network literature gradually began to rise, and its development faster and faster, and even has to present our contemporary cultural development caused some impact. Although the significance of the network literature to some extent, to the development of contemporary Chinese culture brought its development is more mature, but still the current network literature there are still shortcomings more or less. This article will analyze and discuss the importance of network literature in Chinese contemporary literature development, and a brief analysis on the basis of its own deficiencies exist, hoping to bring some reference for the development of China's current network literature and reference value.
\end{abstract}

\section{Introduction}

With the advent of the information age, the Internet-related information and technology more and more mature, the current network as a new media, with the accelerating pace of development and the gradual deepening has become important to spread Chinese contemporary literature way. With the growing popularity of Internet technology, network literature began to emerge in the world, and with its development have been gradually accepted by the public, the network literature to study the writings also increasing, at the same time that, from the government side, the network literature also it has been incorporated into the scope of social science courses planned in various regions. Therefore, in the current social context, the development of the network of literature and Chinese contemporary literature research and analysis, has a very important theoretical and practical significance.

\section{The Importance of Networks Literature in the Development of Chinese Contemporary}

With the rapid development of the current network literature, to a certain extent, so that active and participatory lovers of literature has been improved, but also effectively promote the prosperity and development of popular literature. The rise of network literature, traditional literature mainstream political and social situation gradually break close ties to promote the popularization rate of formation of culture gradually accelerated [1]. From the point of view in terms of literary authors, writers on the Internet in real life most varied career, almost every person engaged in the work are not the same, for example: the network out of network more literary authors Cang and the moon, the former is a female architect, while the latter is a civil servant. Furthermore, the network of professional writers writers, there are amateur literature lovers. From the network in terms of the purpose of writing literature, some take the easy route of entertainment, such as Cang novels, historical fiction moon; while others are writing fiction network to increase their income. From the point of view of writing in terms of resources, most writers on the Internet are subject to the influence of popular literature and nurtured. From the network in terms of literature, most popular works are the subject of martial arts fantasy, suspense reasoning and youth campuses, such as Tang three little "mad god", I love to eat tomatoes, "dragon" and so on. These factors have resulted in the development of contemporary literature and faster speed of the network, thus contributing to Chinese Contemporary Literature territory suffered some degree of change [2].

In some ways in terms of the rapid development of the network literature, the contemporary 
Chinese literature system caused a very strong influence, but also to the prosperity of folk literature can be truly realized. It cannot be denied that the Chinese system has been gradually inviting contemporary exhibit a certain degree of rigidity, which is the development of literature had a significant impact. With the development and rise of the network literature, to a certain extent, so that the rigid system of literature contemporary literature is gradually being broken, he made out a very important role. Literary writing standards allow network decreased, prompting the writing team to grow more and more, so that more people can join the ranks of literary creation. These authors are coming from all walks of life in the real world, by means of a network to be able to let their favorite characters freely create, derive the joy of creating. And with the network literature is gradually accepted by people, professional networks writers gradually began to emerge, they create a network literature to their own lives as economic security, their works were published in the major sites, in order to gain traffic to click to get the appropriate amount of profit [3]. Through its own network of talented writers and literary skills, by means of written expression online readers to get clicks, it can be said to some extent outside the system so that writing can be achieved. These networks are not writers writers have prepared, but do not enjoy the preparation writers should enjoy the treatment, therefore, the writing system cannot make them subject to constraints, which prompted freelance writing some extent gradually realized the true driving force of Folk Literature prosperity and prosperity.

Want to achieve prosperity and development of literature, it is necessary to include an diversified development approach. First, with the rise of network literature, fresh writing experience available to literary creation, but also to some extent on the system of discourse of contemporary literature summary and overview, it brought new for the diversified development of contemporary literature development approach [4]. Let the network literature literary performance space has been expanded. Folk online writers with their own practical experience, the use of popular humorous speech, showing the bottom of society folk wisdom and life experience, fresh blood injected into the Chinese contemporary literature. Meanwhile, the network language is increasing, which were used in the literature, can be a more relaxed. Pleasant reading environment to create out, which also contributed to literary performance space to a certain extent gradually expanded. Secondly, the gradual rise of the network literature, writing methods to achieve the freedom of the imagination style. Let people know how the creation of literature, not only dependent on life experience and practical experience, but also need to have a large OF thinking imagination. Many network original works, such as horror fiction, fiction and fantasy novels Tomb, more is needed a certain author's imagination. In addition, let the Chinese contemporary literature development style becomes richer gradual rise of the network literature has to a certain extent. For now, the more popular network of interactive fiction, literature and other text messages, by means of the network are only gradually rise of a new literary style, which also represents a real network literature. For example: the more popular multimedia novel "Haha, university", by means of which a lot of means of expression, so that the traditional literary phenomenon can only be changed to read, so listen, read the play in the form of progressive realization [5]. With the increasing popularity of mobile phones in the contemporary society, SMS literature has gradually been rapid development, many reflect real life and has a strong expressive messages began to appear. In real life the process, a number of text messages sent or even reach a million times, it can be seen from the text of the charm.

\section{Shortcomings of Network Literary in the Development of Chinese Contemporary Literature}

Literature from the network's point of view upstream, due to the different authorship, and its overall quality literature there are also very different. According to relevant survey, many network contemporary writing hand, many authors have not been through the system, strict training literature, there is a certain lack of literary skills and, thus, to promote the depth and breadth of his work exist serious deficiencies, leading to the current network Literary works are also generally low quality, which also makes an important reason why the network literature classics not appear. Thus, the overall level of network contemporary literary works need to be further improved.

As business networks and professional networks literary writers appear, in order to allow work to 
get traffic and profits increase, the network literature gradually began to use its commercial strategy, which resulted in a number of network literature too much emphasis on "pretty level" to make content the depth and breadth of gradually missing. On some networks in order to allow the amount of reading would be enhanced to get more benefits, even to cater to some of the readers have fun reading vulgar [6]. For example: Mystery fiction plot more and more bizarre, campus novel description of sex scenes more and more and more.

\section{Conclusion}

All in all, the network literature has both a very important and active role in the development of Chinese contemporary literature, but also has a lot of deficiencies. But in terms of overall value, the network literature on the development of Chinese contemporary literature or made out to a large extent the contribution which can gradually rise in a short time, and the current reading needs very appropriate. Thus, while there is a degree of its shortcomings and flaws, but still can not deny that it has a more broad space for development.

\section{References}

[1] Liu Zhiquan. Contemporary literature Transformation Cyber Criticism Space - Also on the number of characteristics of the network literature [J]. Nanjing Normal University (Social Science Edition), 2003,03: 134-140.

[2] Ma Jianguo. You and me to participate freely in hypertext literature - literature features several network popularization click [J]. Anhui Literature (second half), 2009, No.31005: 368-370.

[3] Ji jin. The season as the Chinese Literary World Literature - Translation and dissemination of contemporary literature as an example [J]. Chinese Comparative Literature, 2014, No.9401: 27-36.

[4] Yang bingzhong. Network Literature at New Century: Writing Revolution (Network Research Papers series of literature) [J]. Guangxi Normal University for Nationalities, 2012, v.29; No.8102: 45-49.

[5] Hu Tiesheng. Interaction between literary development and globalization factors - comparative study [J]. Chinese and American Literary History of the Development of the factors of globalization Learning and Exploration, 2005, 02: 94-100.

[6] Yang Bin. Realistic Literature distortion in contemporary literature, restore and deepen [J]. Academic Forum, 2002, 02: 90-93. 